\title{
Effectiveness of Evodiamine and Evodone as Ovarian Anticancer In Silico
}

\author{
Erlix Rakhmad Purnama \\ Department of Biology \\ Universitas Negeri Surabaya \\ Surabaya, Indonesia \\ erlixpurnama@unesa.ac.id \\ Muhammad Ongky Muji Handoyo \\ Department of Biology \\ Universitas Negeri Surabaya \\ Surabaya, Indonesia
}

\author{
Ghea Dionita Sanora \\ Department of Biology \\ Universitas Negeri Surabaya \\ Surabaya, Indonesia
}

\author{
Elly Yana Mastura \\ Department of Biology \\ Universitas Negeri Surabaya \\ Surabaya, Indonesia
}

\begin{abstract}
Cancer is a disease that is still a global problem which ranked second leading cause of death, amounting to $13 \%$ after cardiovascular disease. Cancer of the ovaries arethe second most common group of gynecologic cancers and accounts for about $5 \%$ of all women's cancers. Chemotherapy (chemo) is the use of drugs to treat cancer. Chemo can be useful to kill very small amounts of cancer cells that may still be around after surgery, for cancers that have metastasized (spread), or to shrink very large tumors to make surgery easier. Chemo drugs can cause side effects. These side effects usually go away after treatment is finished. Therapeutic herbs and their derivative phytocompounds are being progressively more accepted as useful complementary treatments for cancer. Zodia (Evodia sp) is Indonesian endemic plants containing some active compounds as anticancer there are evodiamine and evodone. In this study, we investigated the effectiveness of evodiamine and evodone by in silico method to treat varian cancer. This study uses Autodock, PyRx and LigPlot software with the method used is molecular docking. The docking results showed the effectiveness of the two compounds was assessed from binding affinity on evodiamine of $-7 \mathrm{kcal} / \mathrm{mol}$ RMSD (Root Mean Square Deviation) of $1.66 \AA$, while the evodone compound was $-5.8 \mathrm{kcal} / \mathrm{mol}$ and $2.52 \AA$. From these results, can be proven that the evodiamine compound has the most effective results as an ovarian anticancer compound in silico.
\end{abstract} silico

Keywords- Evodiamine, Evodone Anticancer, Ovarian, in

\section{INTRODUCTION}

Among gynecological cancers, ovarian cancer ranks the first lethally rate during the last decades. More than $70 \%$ of women in the world with ovarian cancer diagnosed at an advanced stage. It is one for the reasons of the cause high mortality rate (1). There is no specific symptoms in patients with ovarian cancer in the early stage. If the patient can be detected at an early stage, the survival rates can become around $80 \%-90 \%$ (2). The causes of most ovarian cancer remain unknown. Surgery and effective radiotherapy are given in early cancers, whereas for metastatic cancers the right treatment is a combination of surgery, radiotherapy, and chemotherapy (3). Chemotherapy also causes nausea to anorexia in patients, affects normal cells around cancer cells, and some drugs cannot be combined because it can strengthen the work of other drugs thereby increasing their side effects to cause death (4). In recent years, a growing number of clinical studies showed Chinese Herbal Medicine (CHM) could alleviate chemotherapy-related side effects and improves human immunity responses, which can be a supporting therapy of the adjuvant treatment for ovarian cancer (5).

Indonesia is the second highest biodiversity country and at least 30,000 plant species live in Indonesia, of which 9,600 are known to have medicinal properties. But only 300 species have been used as components of herbal therapeutics (6). In Indonesia, here are Zodia plants (Evodia sp.) which are endemic plants originating from Papua. Previous studies said that the evodiamine compounds in Zodia (Evodia rutaecarpa), has been shown to have anticancer activity both in vitro and in vivo by inhibiting proliferation, invasion, and metastasis of cancer cells, and inducing apoptosis of various types of tumor cells. (7). To find out the potential of active compounds contained in natural products can be done through an in silico computational approach. Eliminating compounds that have a low activity can be done effectively and can know the interaction of compounds with the target and the possibility of toxicity of these compounds (8). Evodiamine and Evodone are active compounds contained in Zodia. Both of these compounds are known to have similar structures. Evodiamine has been shown to have anticancer activity both in vitro and in vivo by inhibiting the proliferation, invasion and metastasis of cancer cells, and inducing apoptosis of various types of tumor cells (8). Some docking studies investigating PI3K $\alpha /$ ligand or $\mathrm{PI} 3 \mathrm{~K} \alpha /$ inhibitor interactions have been published. So we need to investigate the effectiveness of evodiamine and evodone as candidates for anti-ovarian cancer drugs by computational aided-drugs design.

\section{METHODS}

\section{A. Preparation}

Virtual screening is carried out to determine the target of compound activity through the Swiss Target Prediction webserver, the evodiamine is known to have targeted activity on the PI3K protein (ovarian cancer biomarker). Collection of evodiamine and evodone compounds downloaded from 
NCBI: Pubchem database and stored in SDF format. The $\mathrm{PI} 3 \mathrm{~K}$ protein is downloaded from the Protein Data Bank (PDB) database with the 3HHMode stored in the .pdb format.

\section{B. Molecular Docking}

The molecular docking test between evodiamine, evodone, native ligand (Wortmannin), and 3HHM protein was carried out in PyRx software. The docking test will be known the value of binding affinity and Root Mean Square Deviation (RMSD) of the interaction between compounds with proteins and ligands with proteins. To see the visualization, the docking results are directed to the LigPlot++ software in 2D so that it can know the type of bond, the amino acid that is the binding site, and the residual amino acid that is the interaction between the compound with the protein and the ligand with the protein.

\section{Data Analyse}

Data obtained from the docking test between the compound with protein and ligand with protein were compared binding affinity, Root Mean Square Deviation (RMSD), type of bond, and amino acids which are binding sites on proteins (9).

\section{RESULTS AND DISCUSSION}

The PI3K signaling pathway is an important signal transduction pathway for cellular metabolism and is antiapoptotic. PI3K gene is genetically mutated or overexpressed in a wide variety of cancers including ovarian, breast, prostate, gastric, colorectal, glioblastoma, endometrial and brain cancers. The activation of PI3K/AKT signaling pathway is common in ovarian cancer, and this pathway is closely linked with carcinogenesis and metastasis (10). To promoting the transfer of ovarian cancer cells, PI3K can upregulate the expression of matrix metalloproteinase (MMP)-2 and MMP-9 mRNA and degrade extracellular matrix (11). The PI3K/AKT/m-TOR signaling pathway is elaborate in various vital cellular, so many diseases arise as a result of dysregulation or mutation of $\mathrm{PI} 3 \mathrm{~K} / \mathrm{AKT} / \mathrm{m}-\mathrm{TOR}$ pathway, specifically cancer.

The PI3K inhibitor, Wortmannin (Fig. 1a), have been used as tools in preclinical experiments to demonstrate the biological relevance of PI3K (Fig. 1b) and investigate its potential as a therapeutic target in cancers (12). Some docking studies examining PI $3 \mathrm{~K} \alpha /$ ligand or PI3K $\alpha /$ inhibitor interactions have been published. Wortmannin is an irreversible noncompetitive inhibitor of $\mathrm{PI} 3 \mathrm{~K}$ could be decreased cells viability and the percentage of viable cells, whereas it increased cytotoxic activity and also enlarged the percentage of apoptotic cells without change in ROS production (13).

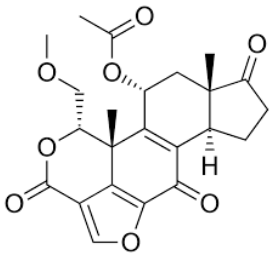

(a)

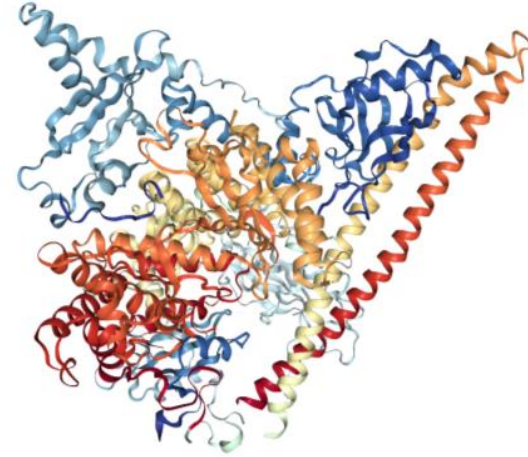

(b)
Fig 1. (a) Inhibitor Wortmannin, (b) PI3K protein (3HHM)

The best docked conformations were selected based on the lowest docking energy (binding energy) of docked complex, number of interacting residues and number of hydrogen bonds (14). Our study exposed that, evodiamine showed properties the best binding towards 3HHM we have screened. Evodiamine showed its better inhibitory activity against 3HHM than evodone or wortmannin as the original nhibitory (Table 1).

\section{TABLE I. THE RECEPTOR LIGAND INTERACTION DATA OBTAINED FROM THE DOCKING STUDIES}

\begin{tabular}{|l|c|c|c|}
\hline Parameters & $\begin{array}{c}\text { Evodiamine } \\
\text { - 3HHM }\end{array}$ & $\begin{array}{c}\text { Evodone - } \\
\text { 3HHM }\end{array}$ & $\begin{array}{c}\text { Wortmannin } \\
-\mathbf{3} \text { HHM }\end{array}$ \\
\hline $\begin{array}{l}\text { Binding } \\
\text { Affinity } \\
\text { (kcal/mol) }\end{array}$ & -5.8 & -7 & -8.2 \\
\hline RMSD $(\AA)$ & 2.522 & 1.662 & 3.269 \\
\hline Bond Type & Hydrogen & Hydrogen & Hydrogen \\
\hline
\end{tabular}

Evodiamine is a natural indole alkaloid extracted from the fruit of Evodia rutaecarpa and a multitarget compound having a wide spectrum of biological activities (14). Evodiamine poses favorable properties in inflammation, infectious disease, and Alzheimer's disease and has antioncogenes actions in several cancer cells. Evodiamine arrests cancer cell cycle distributions and induces cell apoptosis to play a role in antitumor growth (15). Previous studies have indicated that evodiamine-induced $S$ phase arrest (15), blockage of cells in the G2/M phase (16), inhibited the growth of thyroid cancer (17), and antimetastatic agents acting through the inhibition of colon cancer cell migration without cytotoxicity (18).

In summary, evodiamine is more effective than evodone and Wortmannin as ovarian anticancer compound. It has the best binding affinity $-7 \mathrm{kcal} / \mathrm{mol}$ and also RMSD $1.662 \AA$. So, evodiamine can used as candidate of ovarian anti-cancer drugs based on computational aided-drugs design.

\section{REFERENCES}

[1] Lindsey A., Farhad I., et. al., Global Cancer in Women: Burden and Trends, Cancer Epidemiol Biomarkers Prev, Vol. 26, 2017, pp. 444457.

[2] Francesmary M., Robert P., Ovarian Cancer: Prevention, Detection and Treatment of the Disease and Its Recurrence. Molecular 
Mechanisms and Personalized Medicine Meeting Report, Int J Gynecol Cancer, Vol. 22, 2012, pp. 45-57.

[3] Bakhtiar, A., \& Soeprijanto, B. (2006). Kanker Paru dan Penatalaksanaannya. Jurnal Kedokteran Syiah Kuala, 6(1), 23-37.

[4] Lander, E. S. . L., Birren, L. M. ., Nusbaum, B., Zody, C., Baldwin, M. C. ., Devon, J., ... McKernanKevin., P. (2001). Initial sequencing and analysis of the human genome. Nature, 409(April 2014), 860 921.

[5] Hao Y, Zhang X. TCM therapy for ovarian cancer research and analysis. J Pract Trad Chin Inter Med. (2011) 7:35-6. doi: 10.13729/j.issn.1671-7813.2011.07.014

[6] Kementrian Kesehatan RI. (2007). KEPMENKES 381-2007 KEBIJAKAN OBAT TRADISIONAL (pp. 1-27). pp. 1-27.

[7] Jiang, J. and Hu, C. (2009) 'Evodiamine: A Novel Anti-Cancer Alkaloid from Evodia rutaecarpa', Journal Molecules, 14, pp. 1852 1859 .

[8] Meng, X.-Y., Zhang, H.-X., Mezei, M., \& Cui, M. (2011). Molecular Docking: A Powerful Approach for Structure-Based Drug Discovery. Current Computer Aided-Drug Design, 7(2), 146-157.

[9] Suvannang, N., Nantasenamat, C., Isarankura-Na-Ayudhya, C., \& Prachayasittikul, V. (2011). Molecular docking of aromatase inhibitors. Molecules, 16(5), 3597-3617.

[10] Zhang, L. Q. et al. (2019) 'CNDP2 Acts as an Activator for Human Ovarian Cancer Growth and Metastasis via the PI3K/AKT Pathway', Technology in Cancer Research \& Treatment. 18, pp. 1-10

[11] Ahn, JH, Lee, KT, Choi, YS, Choi, JH. Iloprost, a prostacyclin analog, inhibits the invasion of ovarian cancer cells by downregulating matrix metallopeptidase-2 (MMP-2) through the IP-dependent pathway. Prostag Oth Lipid M. 2018;134:47-56.

[12] Leary, A., Auclin, E., Putier, P., and Lhomme., C. (2013). The PI3K/Akt/mTOR Pathway in Ovarian Cancer: Biological Rationale and Therapeutic Opportunities. In Book Ovarian Cancer Chapter 13. Editor: Ivan Diaz-Padilla. IntechOpen Limited: UK. pp: 275-302.

[13] Kim, S.H., Kang, J.G., Kim, C.S. et al. Endocrine (2019) 65: 110.

[14] J. Jiang, C. Hu, Evodiamine: a novel anti-cancer alkaloid from Evodia rutaecarpa. Molecules 14, 1852-1859 (2009)

[15] Du, Jia., Wang, X-F, Zhou, Q-M, et al. (2013). Evodiamine induces apoptosis and inhibits metastasis in MDA-MB-231 human breast cancer cells in vitro and in vivo. Oncology Reports. Vol. 30. pp: 685694.

[16] Zhang C, Fan X, Xu X, Yang X, Wang X and Liang HP: Evodiamine induces caspase-dependent apoptosis and $S$ phase arrest in human colon lovo cells. Anticancer Drugs 21: 766-776, 2010.

[17] Kan SF, Huang WJ, Lin LC and Wang PS: Inhibitory effects of evodiamine on the growth of human prostate cancer cell line LNCaP. Int J Cancer 110: 641-651, 2004.

[18] Ogasawara M, Matsubara T and Suzuki H: Screening of natural compounds for Inhibitory activity on colon cancer cell migration. Biol Pharm Bull 24: 720-723, 2001.

[19]

[20] J. Clerk Maxwell, A Treatise on Electricity and Magnetism, 3rd ed., vol. 2. Oxford: Clarendon, 1892, pp.68-73.

[21] I. S. Jacobs and C. P. Bean, "Fine particles, thin films and exchange anisotropy," in Magnetism, vol. III, G. T. Rado and H. Suhl, Eds. New York: Academic, 1963, pp. 271-350.

[22] K. Elissa, "Title of paper if known," unpublished.

[23] R. Nicole, "Title of paper with only first word capitalized," J. Name Stand. Abbrev., in press.

[24] Y. Yorozu, M. Hirano, K. Oka, and Y. Tagawa, "Electron spectroscopy studies on magneto-optical media and plastic substrate interface,” IEEE Transl. J. Magn. Japan, vol. 2, pp. 740-741, August 1987 [Digests 9th Annual Conf. Magnetics Japan, p. 301, 1982]

[25] M. Young, The Technical Writer's Handbook. Mill Valley, CA: University Science, 1989 